MATEC Web of Conferences 22,02012 (2015)

DOI: $10.1051 /$ matecconf/ 20152202012

(C) Owned by the authors, published by EDP Sciences, 2015

\title{
Erosion of Premium Connection Cross-over Joint in Solid-liquid Flow
}

\author{
Yong'an Zhao \& Wenbin Cai \\ Baoshan Iron \& Steel Co., Ltd., Shanghai, China
}

Lu Cui

School of Mechanical Engineering, Xi'an Shiyou University, Xi'an, Shaanxi, China

Jiarui Cheng

State Key Laboratory of Multiphase Flow in Power Engineering, Xi'an Jiaotong University, Xi'an, Shaanxi, China

Yihua Dou

School of Mechanical Engineering, Xi'an Shiyou University, Xi'an, Shaanxi, China

\begin{abstract}
Hydraulic fracturing is a new technique which is used in oil yield to maximize its own production. The pumping of fracturing slurry flow through tubing collar can cause considerable mass loss of inner surface materials. This may pose a significantly potential risk even a well loss. Especially, the erosion phenomenon is particularly serious in the structure of variable diameter. Numerical simulation in this paper was used to get particle impact parameters, and it is combined with jet experiments to find out the main factors of BG- $13 \mathrm{Cr}$ mass loss. Finally, the equation with experimental data was applied to predict erosion rate of premium connection cross-over joint inner wall.
\end{abstract}

Keywords: premium connection; erosion rate; numerical simulation; Jet flow experiments

\section{INTRODUCTION}

Hydraulic fracturing is a new technique that a high-pressure liquid fluid is injected to a wellbore in order to create small fractures in the deep-rock formations and in order to allow natural gas, petroleum, and brine to migrate to the well.[1] The development of fracture which in the carrier fluid of higher pump rates and two-phase flow condition of proppant volumes may cause more and more severe problems for intense erosion, which leads to short service time of well tubing.[2] In particular, the change of solid velocities and impact angles in the location of structural breaks will enhance the material loss. In addition, mass loss existing in the inner wall of tubing is often caused by the aerobic corrosion or mechanical erosion, or the synergistic effects of them.

As this issue has been recognized, some measures are taken to prevent erosion and corrosion. For example, we use stainless steel instead of carbon steel because the passive film on the stainless steel surface can resist oxygen reacting with iron. However, the high velocity particles' impacts on the inner surface such as tubing collar, that can't be avoided causing a large amount of material loss.

In this paper, the CFD method was used to get particle parameters combined with the semi-empirical erosion equation which was obtained from jet flow experiments. Then the inner wall erosion rates of premium connection cross-over joint were calculated by particle impact velocities and angles.

\section{EXPERIMENTAL PROCEDURE}

The erosion studies were carried out in a jet flow experimental apparatus and shown in Figure 1. It is consisted of a large stainless steel tank $(30 \mathrm{~cm}$ in length, $30 \mathrm{~cm}$ in width, and $40 \mathrm{~cm}$ in height) from which the liquid solution (with or without particles) was using a calibrated pump. The flow rate of the liquid was controlled by a bypass line and was measured by a magnetic flow meter.

An aqueous solution contained $3.5 \% \mathrm{wtNaCl}$ (analytical grade) in twice-distilled water of $\mathrm{pH} \mathrm{6.7,} \mathrm{and}$ formed the fluid jet. As shown in Figure 1, the erosion-corrosion measurements were operated to use the jet test cell. In this situation, the impact angle was fixed at $90^{\circ}$ (normal incidence) and the exit nozzle of the fluid jet was made of stainless steel 304 . The samples were made of $\mathrm{BG}-13 \mathrm{Cr}$ with dimensions of $20 \times 20 \mathrm{~mm} 2$ and $5 \mathrm{~mm}$ in thickness. The test surface of each specimen was encased in a polymethyl methacrylate (PMMA) insulating sheet, sealed with epoxy resin and ground using $\mathrm{SiC}$ emery paper grade 1200. The chemical composition of the BG-13Cr stainless steel is presented in Table 1 and the main parameters of particles are shown in Table 2. 


\section{MATEC Web of Conferences}

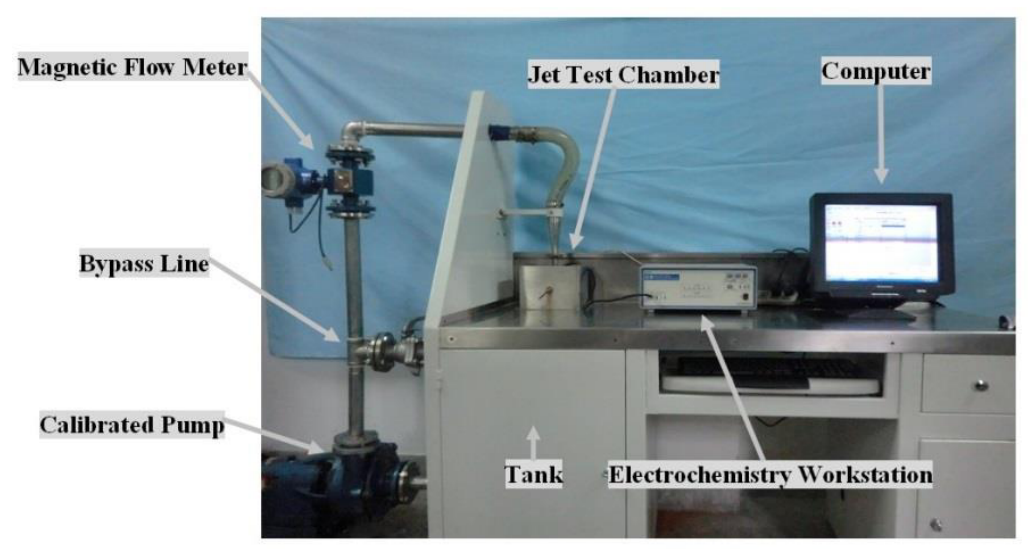

Figure 1. Jet flow experimental system

Table 1. Chemical composition of BG-13Cr stainless steel used in the experiment

\begin{tabular}{lllllllll}
\hline Composition (wt\%) & $\mathrm{C}$ & $\mathrm{Cr}$ & $\mathrm{Mo}$ & $\mathrm{Ni}$ & $\mathrm{Si}$ & $\mathrm{Mn}$ & $\mathrm{S}$ & $\mathrm{P}$ \\
\hline BG-13Cr & 0.03 & 13.5 & 3.0 & 6.5 & 0.21 & 0.45 & 0.002 & 0.015 \\
\hline
\end{tabular}

Table 2. Parameters of particle used in erosion testing

\begin{tabular}{lll}
\hline Parameter & $\begin{array}{l}\text { Diameter } \\
(\mathrm{mm})\end{array}$ & $\begin{array}{l}\text { Mass } \\
(\mathrm{mg})\end{array}$ \\
\hline Sphere particle & $0.6 \pm 0.03$ & $0.4 \pm 0.05$ \\
\hline
\end{tabular}

\section{COMPUTATIONAL FLUID DYNAMIC}

The FLUENT6.3 commercial CFD software was used to predict the premium connection cross-over joint erosion. In this section, the solid-liquid two-phase methods include Renormalization Group Method for the continuous phase [3] and Lagrangian tracking model [4] for particles were used to obtain the value of particle impact velocities and angles, and then calculated the erosion rate of inner wall. Once a steady state solution was obtained for the liquid, the paths of sand particles released from the solid inlet were tracked through the flow domain. The design features of the premium connection cross-over joint are shown as follows (Figure 2):

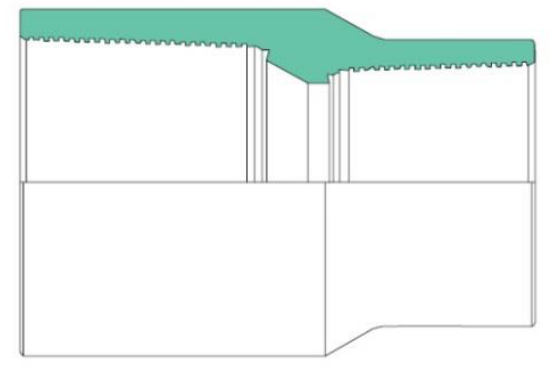

Figure 2. Premium connection cross-over joint geometry
(1)Alternative coupling diameter or thread change is adopted with female threads in both ends;

(2)Thread and seal plane are copper-plated;

(3)Be manufactured by precision NC machine.

In this case, the mesh of premium connection was applied to the geometry using the GAMBIT2.4.6 meshing software (Figure 3). The SIMPLE algorithm was used for discretizing the equations, a second-order upwind scheme was used for the convective term, and a central difference method was used for the diffusion term. All walls were modeled as solid no-slip boundaries, and a symmetry boundary condition was used for the liquid surface where zero normal velocity and zero normal gradients for all variables are satisfied.

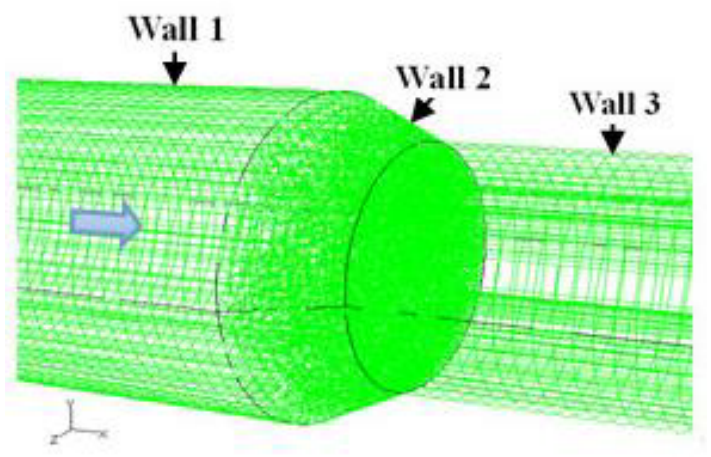

Figure 3. Premium connection cross-over joint mesh 


\section{RESULTS AND DISCUSSION}

Most of semi-empirical erosion models were developed by authors, such as Grant and Tabakoff (1973)[5], Ahlert(1994)[6], Oka and Yoshida(2005)[7]. In this paper, the erosion rate of BG- $13 \mathrm{Cr}$ sample was considered to use an erosion sub-model based on which was proposed by Chen et al.[8][9]. And the Erosion is a calculation using Eq.(1):

$$
E=K v^{n} f(\alpha)
$$

Where $\mathrm{E}$ is the erosion rate on the sample surface, $v$ and $\alpha$ are the particles' impact velocity and angle, $\mathrm{K}$ is the constant and $\mathrm{n}$ is the impact velocity power law coefficient. $F(\alpha)$ is angle function which describes the impact angle effect of erosion rate. This function was described by Chen et al [8] as follows:

$$
f(\alpha)=\left\{\begin{array}{cc}
A \alpha^{2}+B \alpha & ; \quad \alpha \leq \varphi \\
X \cos ^{2} \alpha \cdot \sin (W \alpha)+Y \sin ^{2} \alpha+Z ; & \alpha>\varphi
\end{array}\right.
$$

Where, $A, B, X, W, Y, Z$ and $\varphi$ are all empirical coefficients.

In this paper, $n$ and $f(\alpha)$ obtained by jet flow experimental data fitting (Figure 4 and Figure 5).The final $\mathrm{BG}-13 \mathrm{Cr}$ steel erosion equation is shown as follows:

$$
\begin{aligned}
& E_{13 C r}=4.1 \times 10^{-10} v^{1.57} f(\alpha) \\
& f(\alpha)=\left\{\begin{array}{ccc}
2.56 \times 10^{2}-3.02 \alpha & ; \quad 0<\alpha \leq 70^{\circ} \\
-2.89 \times 10^{2}+4.77 \alpha & ; & 70^{\circ}<\alpha \leq 90
\end{array}\right.
\end{aligned}
$$

The flow through the erosion rate was calculated and used Eq. (3), and results are presented in the following figures.

Figure 6 pictorially summarizes the correlation of the fluid streamlines with the surface profile of the drawing down. As the flow enters the premium connection and passes over the Wall 2, the streamlines converge and streamwise velocities in the small chamber are expected to increase accordingly. When particles are entrained in this reversing flow, they probably (especially those with a local Stokes number that are much greater than unity) cross the streamlines and impact the Wall 2, and subsequently erode the material there (Figure 7). This is the Stokes number, St, which is generally defined as follows[10]:

$$
S t=\frac{u \tau}{l}
$$

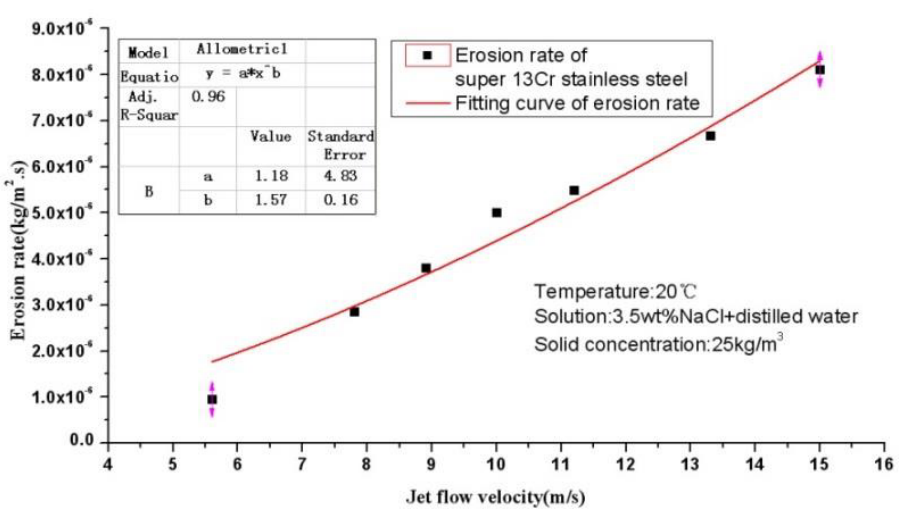

Figure 4. Fit curve of BG-13Cr experimental values based on different jet flow rates

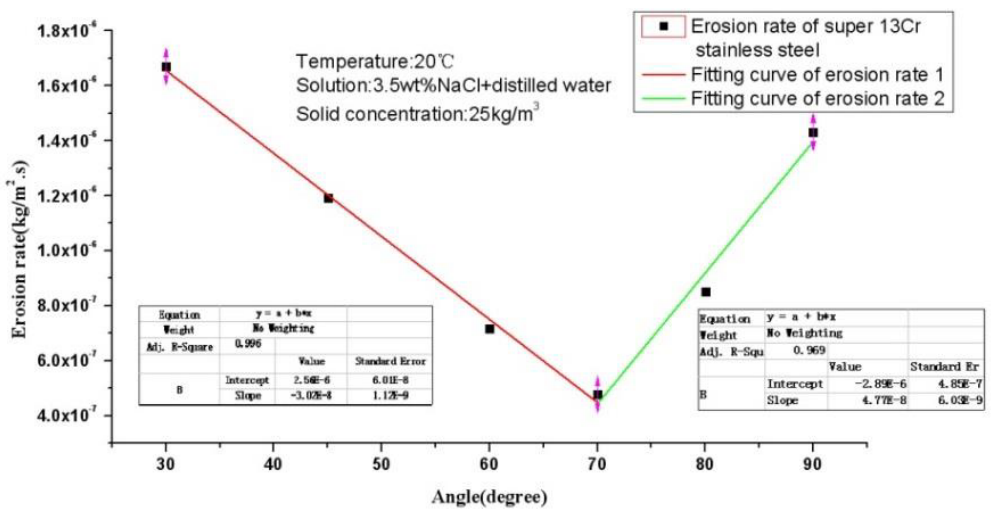

Figure 5. Fit curve of BG-13Cr experimental values based on different particle impact angles 


\section{MATEC Web of Conferences}

Where, $\mathrm{u}$-local liquid velocity, $\mathrm{m} / \mathrm{s}$;

1 -a reference length. It is the particle diameter $d_{p}$, $\mathrm{m}$;

$\tau$ —-shear stress between liquid and particle, $\mathrm{Pa}$.

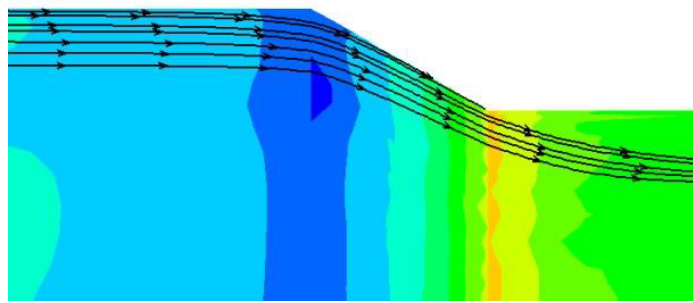

Figure 6. Contours of velocity in premium connection for flow of water at $29.41 \mathrm{~m} / \mathrm{s}$

To calculate the premium connection inner wall erosion rate, 480 particle trajectories were tracked at a flow rate of $29.41 \mathrm{~m} / \mathrm{s}$. The Figure 7 shows that the most erosion in the test section occurs in the Wall 2, which with a lesser amount on the other surfaces is shown in Figure 8. The rate of material removal on the Wall 1 is 2 to 5 orders of magnitude, which is smaller than that on the Wall 2.

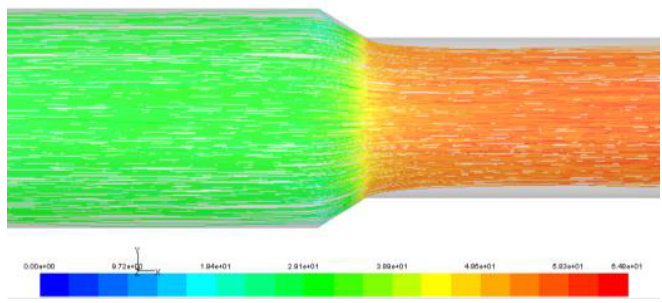

Figure 7. Particle tracks through the premium connection

Figure 9 shows different directions velocity components of impact particles on the wall 2.And the absolute velocity is almost affected by X-direction velocity. So the erosion theoretical values are calculated by Eq. (3).

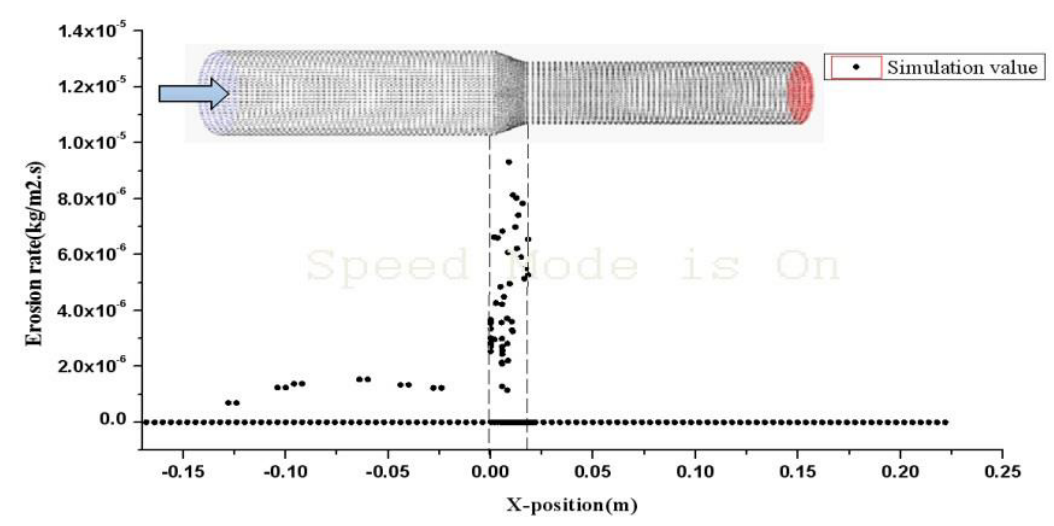

Figure 8. Simulation results of erosion rate in different inner walls

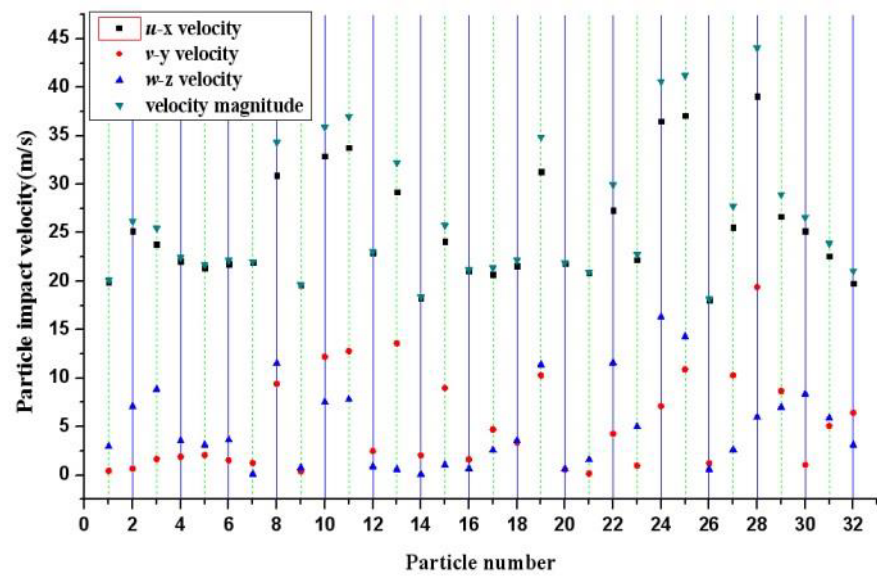

Figure 9. Particle impact velocities from different directions 
ICETA 2015

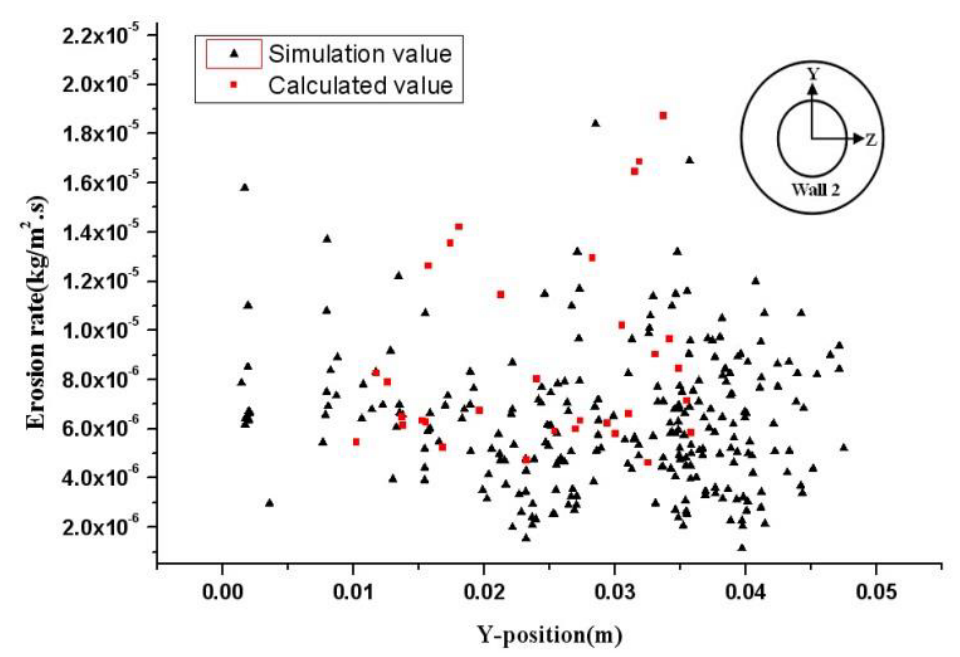

Figure 10. Erosion rate of wall 2 among simulation and experimental results

The results of CFD analysis and theoretical calculation value are similar and closed to $10-6 \mathrm{~kg} / \mathrm{m} 2 \cdot \mathrm{s}$ $(10-1 \mathrm{~mm} / \mathrm{h})$ (Figure 10). Furthermore, the rate of erosion will be linked to the amount of sand pumped to help determine the premium connection life in the field.

\section{CONCLUSIONS}

Flow field have changes in premium connection cross-over joint inner wall, because it had specifically geometries-pipe drawing down, resulting in an accelerated erosion reaction. To predict the erosion of premium connection, the semi-empirical equation obtaining from impingement jet system was employed to calculate. Then flow characteristics in the premium connection were simulated. It was suggested that the most serious erosion area was forward-facing step (FWFS). The results of CFD analysis and theoretical calculation value are similar and closed to $10-1 \mathrm{~mm} / \mathrm{h}$. Finally, the inner structure is changed by serious damage of erosion so that it can lead to a connection failure.

\section{ACKNOWLEDGMENT}

Thanks to the "Gold Apple" project of Baoshan Iron $\&$ Steel Co., Ltd. for financial support.

\section{REFERENCES}

[1] S.H. Shah. \& S. Jain. 2004. Coiled tubing erosion during hydraulic fracturing slurry flow, SPE/ICoTA Coiled Tubing Conference and Exhibition held in Houston, Texas, U.S.A., 23-24 March.
[2] Rezsa Farahani. \& Marty Lastiwka, et al. 2011. Assessment and prediction of erosion in completion systems under hydraulic fracturing operations using computational fluid dynamics, SPE Annual Technical Conference and Exhibition held in Denver, Colorado, USA, 30 October-2 November.

[3] Z.Yue. \& P. Zhou. 1987. Some factors Influencing corrosion-erosion performance of materials, Wear of Mterials, ASME, New York.

[4] H.X. Guo, B.T. Lu. \& J.L. Luo. 2006. Study on passivation and erosion-enhanced corrosion resistance by Mott-Schottky analysis, Electrochemical Acta, 52: 1114-1116.

[5] Grant. G. \& Tabakoff. W. 1973. An experimental investigation of the erosion characteristics of 2024 aluminum alloy. Cincinnati: Department of Aerospace Engineering, University of Cincinnati, Tech. Rep, 73-37.

[6] Ahlert, K. R. Effects of particle impingement angle and surface wetting on solid particle erosion of AISI 1018 steel. Tulsa: The University of Tulsa.

[7] Oka, Y. I, Okamura, K. \& Yoshida, T. 2005. Practical estimation of erosion damage caused by solid particle impact. Part 1: Effects of impact parameters on a predictive equation. Wear, 259(1-6): 95-101.

[8] X.H. Chen. \& S.Brenton., et al. 2004. Application and Experimental Validation of A Computational Fluid Dynamics (CFD)-based Erosion Prediction Model in Elbows and Plugged Tees. Computers \& Fluid, 33(10): 1252-1254.

[9] U. Lotz. \& J. Postlethwaite. 1990. Erosion-corrosion in Disturbed Two Phase Liquid/particle Flow. Corrosion Science, 30: 95.

[10]B.T.Chao. 1982. Scaling and modeling, in Handbook of multiphase systems, G. Hetsroni, Ed., New York: Hemisphere, McGraw-Hill. 